Cook, H. E. (1970). Acta Met. 18, 297-306.

Соoк, H. E. (1973a). Acta Met. 21, 1431-1444.

Cook, H. E. (1973b). Acta Met. 21, 1445-1449.

CooK, H. E. (1974a). Acta Met. 22, 239-247.

Cook, H. E. (1974b). On First Order Structural Phase Transitions. I. General Considerations of Pre-Transition and Nucleation Phenomena. To be published.

Cook, H. E. (1974c). On First-Order Structural Phase Transitions. II. The Omega Transformation in $\mathrm{Zr}-\mathrm{Nb}$ Alloys. To be published.

Cowley, R. A. (1970). J. Phys. Soc. Japan, Suppl. 28, 239242.

Dawson, C. W. \& Sass, S. L. (1970). Met. Trans. 1, 2225 2233.

Fontaine, D. De \& Buck, O. (1973). Phil. Mag. 27, 967983.

Fontaine, D. DE \& CoOK, H. (1971). Critical Phenomena in Alloys, Magnets and Superconductors, Edited by R. E. Mills, E. Asher and R. I. JAFFe, pp.257-275. New York: McGraw-Hill.

FontAINE, D. DE \& KIKUCHI, R. (1974). Acta Met. 22, 1139-1146.

Frenkel, J. (1946). Kinetic Theory of Liquids, pp. 374-390. Oxford: Clarendon Press.

Goasdoue, C., Ho, P. S. \& Sass, S. L. (1972). Acta Met. 20, 725-733.

Hange, W. \& Bilz, H. (1972). Neutron Inelastic Scattering in 1972, pp. 3-28. Vienna: IAEA.

Khachaturyan, A. G. (1968). Sov. Phys. Solid State, 9, 2040-2046.

Krivoglaz, M. A. (1958), Sov. Phys. JETP, 34, 139150.

KRIVOGLAZ, M. A. (1969). Theory of X-ray and Thermal Neutron Scattering by Real Crystals. New York: Plenum.
Landau, L. D. (1937). Zh. Eksp. Teor. Fiz. 7, 1232-1241.

LANDAU, L. D. \& Lifshitz, E. M. (1958). Statistical Physics. Reading, Mass.: Addison-Wesley.

LANGer, J. S. (1973). Acta Met. 21, 1649-1659.

Moss, S. C. (1969). Phys. Rev. Lett. 22, 1108-1111.

Moss, S. C., Keating, D. T. \& Axe, J. D. (1973). Phase Transformations 1973, Edited by L. E. Cross, p. 179-188. Oxford: Pergamon Press.

Nakagawa, Y. \& Woods, A. D. B. (1963). Phys. Rev. Lett. 11, 271-274.

Overhauser, A. W. (1968). Phys. Rev. 167, 691-698.

Overhauser, A. W. (1971). Phys. Rev. B3, 1884-1898.

Rundman, K. B. (1967). Ph.D. Thesis, Northwestern Univ., Evanston, Illinois.

Sass, S. L. (1972). J. Less-Common Metals, 28, 157-173.

SAss, S. L. \& BORIE, B. (1972). J. Appl. Cryst. 5, 236-238.

SATo, H. \& Tотн, R. S. (1965). Alloying Behavior and Effects in Concentrated Solid Solutions, Edited by T. B. Massalski, pp. 295-419. New York: Gordon and Breach.

Sato, K., Watanabe, D. \& Ogawa, S. (1962). J. Phys. Soc. Japan, 17, 1647-1651.

Shapiro, S. M., Axe, J. D., Shirane, G. \& Riste, T. (1972). Phys. Rev. B6, 4332-4341.

Silcock, J. M., Davies, M. H. \& Hardy, H. K. (1955). The Mechanism of Phase Transformations in Metals, Monograph No. 18, pp. 93-104. London: Institute of Metals.

Sinclair, R. \& Thomas, G. (1975). J. Appl. Cryst. 8, 206210.

Spalt, H., Lin, W. \& Batterman, B. (1975). J. Appl. Cryst. $8,140$.

Watanabe, D. (1959). J. Phys. Soc. Japan, 14, 436-443.

J. Appl. Cryst. (1975). 8, 140

\title{
Study of the $\omega$ Phase in Zr-Nb Alloys by Mössbauer and X-ray Diffuse Scattering
}

\author{
By H. Spalt, W. Lin and B. W. Batterman \\ Cornell University, Ithaca, New York 14850, U.S.A.
}

(Received 29 April 1974)

\begin{abstract}
The $\omega$ phase transformation in $\mathrm{Zr}-\mathrm{Nb}$ alloys has been studied by measuring the $\mathrm{X}$-ray diffuse scattering in the (110) plane and the Mössbauer diffuse scattering along the $\langle 111\rangle$ direction of separate single crystals with compositions ranging from 8 to $30 \% \mathrm{Nb}$. The Mössbauer results show that only the elastic part of the $\omega$ diffuse scattering (i.e. with energy loss less than about $10^{-8} \mathrm{eV}$ ) is shifted from the hexagonal lattice whereas the inelastic portion is centered on the hexagonal lattice. The displacement from the exact hexagonal positions for both the X-ray scattering and the elastic part of the Mössbauer scattering found to be somewhat different from that observed with electron diffraction. The inelastic portion is wider in $k$ space than the elastic, and both are wider than would be expected from the resolution volume. The inelastic-to-elastic peak ratios clearly increase for diffuse $\omega$ peaks further out in $k$ space and for higher $\mathrm{Nb}$ concentrations. The concentration effect is due mostly to a sharp decrease of the elastic part with increased $\mathrm{Nb}$ content. The inelastic portion varies less markedly with composition.
\end{abstract}

